\title{
Cerebral blood flow in the newborn infant
}

\author{
O Pryds, A D Edwards
}

\section{Department of Neonatology, Rigshospitalet, Copenhagen O Pryds \\ Department of Paediatrics and Neonatal Medicine, Royal Postgraduate Medical School, London W12 0NN A D Edwards}

Correspondence to: Professor A D Edwards.
Abnormal cerebral haemodynamics seem to be a significant cause of morbidity and mortality in newborn infants. ${ }^{1}$ However, our understanding of cerebral blood flow (CBF) in this age group remains relatively unsophisticated, and still relies heavily on data obtained from studies of animals or adults. This paper examines the merits and difficulties of methods available for measuring CBF in the newborn, and reviews some current concepts concerning perinatal cerebrovascular physiology.

\section{Quantitative estimation of cerebral blood flow}

Most methods for CBF measurements in humans are based on the Fick principle, which states that the rate of accumulation of a tracer molecule in an organ (dQ/dt) is equal in the difference between the rate of delivery and the rate of removal of that tracer. The rate of delivery is the product of the blood flow to the organ $(F)$ and the arterial concentration $\left(C_{a}\right)$, and similarly the rate of removal is the product of blood flow and venous concentration $\left(C_{v}\right)$. Thus $\mathrm{dQ} / \mathrm{dt}=\left(\mathrm{F} \cdot \mathrm{C}_{\mathrm{a}}\right)-\left(\mathrm{F} \cdot \mathrm{C}_{\mathrm{v}}\right)$, and for the brain, by rearrangement:

$$
C B F=\frac{d Q}{\left(C_{\mathrm{a}}\right)-\left(C_{\mathrm{v}}\right) d t}
$$

As well as accumulation of tracer, the clearance of tracer (which is merely negative accumulation) can be used to measure flow. However, use of the Fick principle involves important assumptions: the substance must be neither consumed by, nor be produced in, the organ; the flow must be constant during the measurement period; and tracers must be either fully diffusible or completely non-diffusible.

Because the tracer is fully diffusible, $C_{v}$ equals $Q(t) . \lambda$, where $\lambda$ is the blood-brain partition coefficient. As $90 \%$ of the ${ }^{133} \mathrm{Xe}$ is cleared during each pass through the lungs, $\mathrm{C}_{\mathrm{a}}$ is close to zero. Any significant recirculation of the tracer which makes $C_{a}$ non-zero can be estimated from the activity in the expired air or by placing a detector over the chest, as alveolar gas is in equilibrium with pulmonary venous blood. A typical clearance curve is shown in fig 1.

The ${ }^{133} \mathrm{Xe}$ clearance technique can be performed in the neonatal unit and has allowed a considerable amount of data to be collected, but it involves exposure to $\beta$, and $\beta$ ionising radiation: using intravenous injection the mount of ${ }^{133} \mathrm{Xe}$ in one $\mathrm{CBF}$ measurement $(20-40 \mathrm{MBq})$ results in a total body radiation dose of $0.2 \mathrm{mGy}(20 \mathrm{mrad})$ which is similar to one to two chest $x$-ray examinations. Measurement also requires several minutes, so that rapid changes in CBF cannot be recorded. ${ }^{2}$

POSITRON EMISSION TOMOGRAPHY

Regional cerebral blood flow, together with glucose and oxygen consumption, can be observed using positron emission tomography (PET). $\mathrm{H}_{2}{ }^{15} \mathrm{O}$ is injected and emits positrons which collide with electrons in tissues, leading to annihilation of the particles and the emission of a pair of $\gamma$-ray photons at an angle of $180^{\circ}$ to each. Suitable detectors can determine the location of the annihilation event, and by comparing the clearance of the positron emitting isotope with the location of the annihilation events, determine regional CBF with a resolution of 3-4 $\mathrm{mm}$.

The ability to measure regional blood flow is a great advantage. Unfortunately PET investigations are limited by the relatively high exposure to ionising radiation of 0.57 $\mathrm{mGy}(57 \mathrm{mrad}),{ }^{3}$ and by the need to draw a substantial volume of arterial blood to quantify CBF results. It cannot yet be performed in the neonatal unit, which further constrains its application to studies of sick newborn infants. inspiratory gas, or a vein, in sufficient quantity to diffuse into the cells of the brain. As it is not metabolised, it can then only be removed from the brain by diffusing back into the blood, and the rate of clearance is proportional to $\mathrm{CBF}$. The brain clearance (-dQ) can be detected by external scintillators placed over the skull and information on global or focal CBF is obtained.

\section{XENON COMPUTED TOMOGRAPHY}

Regional CBF has been measured using stable xenon computerised tomographic scanning (XeCT). ${ }^{4}$ Non-radioactive $\mathrm{Xe}$ is inhaled, resulting in a time-dependent increase in tissue density. CBF is calculated by analysing the 


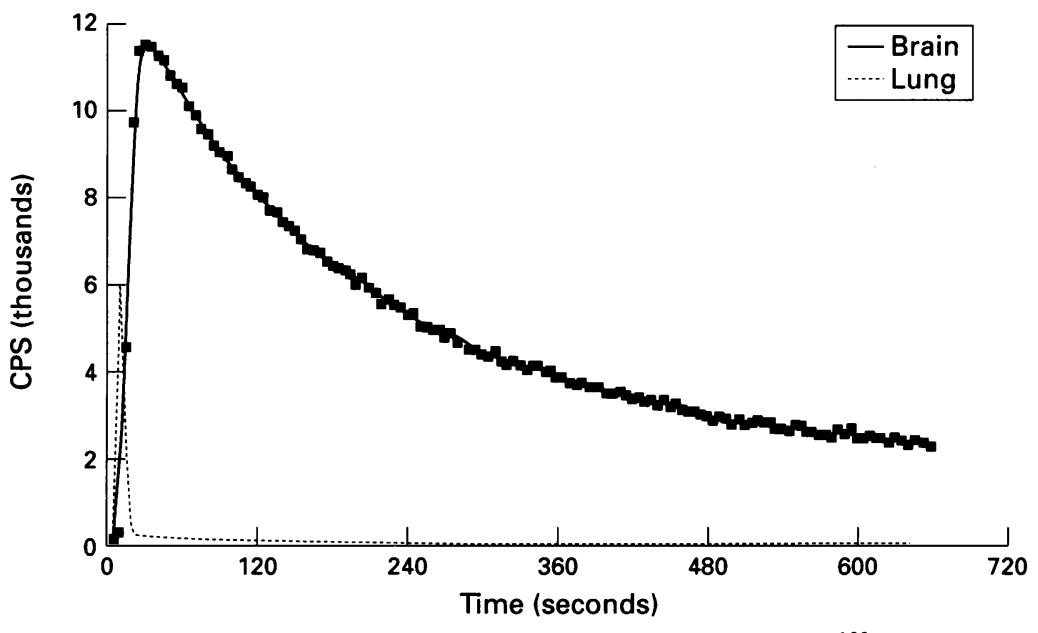

Figure 1 Measurement of cerebral blood flow by intravenous injection of ${ }^{133}$ Xenon. The graph shows the clearance of radioactive tracer from the brain, which is proportional to the rate of cerebral blood flow. measured. If it is less than the vascular transit time no tracer will have appeared in the venous system and $\mathrm{C}_{\mathrm{v}}$ is zero. Thus:

$$
C B F=\frac{d Q}{\int_{0}^{\mathrm{t}}\left(C_{\mathrm{a}}\right) d t}
$$

CBF can be determined from the ratio of the tracer accumulated at time $t$ to the quantity of tracer introduced. Oxyhaemoglobin $\left(\mathrm{HbO}_{2}\right)$ absorbs near infrared light, and can be used as an endogenous tracer: a sudden increase in arterial saturation $\left(\mathrm{S}_{\mathrm{a}} \mathrm{O}_{2}\right)$ over a few seconds is induced by a sharp but transient increase in inspired oxygen concentration. This causes an additional bolus of $\mathrm{HbO}_{2}$ to enter the arterial supply. $\mathrm{C}_{\mathrm{a}}$ is the product of the arterial haemoglobin concentration and the change in $\mathrm{S}_{\mathrm{a}} \mathrm{O}_{2}$ (measured by a pulse oximeter on the face or upper limb). The increase in $\left[\mathrm{HbO}_{2}\right]$ is measured by NIRS. An example of the measurement of CBF measurement by NIRS is given in fig 2 .

The technique involves several assumptions: during measurements, CBF cerebral blood volume and cerebral oxygen extraction must remain constant. However, it has been validated by comparison with established methods of blood flow measurement, and permits rapid, repeated measurements in newborn infants without interrupting normal care. ${ }^{67}$ It has been used for several studies in newborn infants. ${ }^{7}$ NIRS has the advantage of providing other data on cerebral haemodynamics and oxygenation as well as flow, but there are limitations to the $\mathrm{CBF}$ technique, as it is unsuitable for infants with severe lung disease who cannot achieve rapid changes in oxygenation. infant head where some photons are absorbed by pigmented compounds (chromophores) present in the tissue.

CBF is measured using a modification of the Fick principle. In contrast to previously discussed methods, the technique uses a purely intravascular and non-diffusible tracer. This is introduced rapidly into the arterial supply of the brain and the accumulation in the brain is

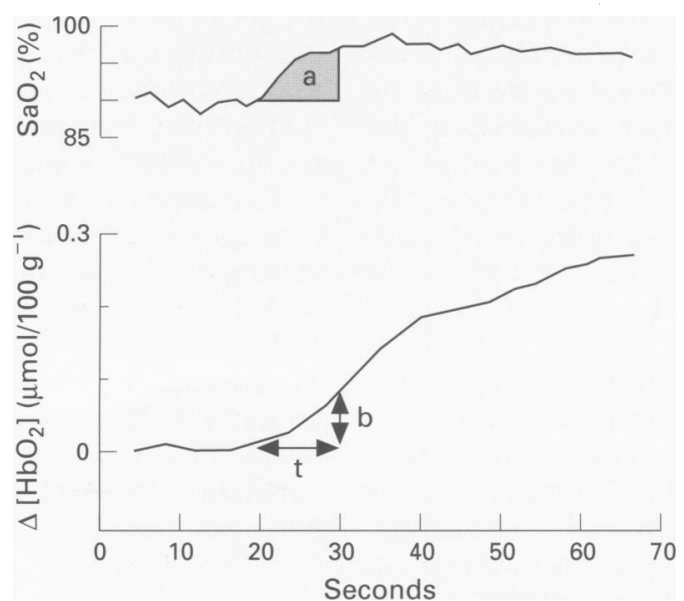

Figure 2 Measurement of cerebral blood flow using near infrared spectroscopy. A sudden change in oxyhaemoglobin concentration is measured in the arterial system by pulse oximeter $\left(\mathrm{SaO}_{2}\right)$ and in the brain by near infrared spectroscopy $\left(\Delta\left[\mathrm{HbO}_{2}\right]\right)$. Cerebral blood flow is quantified by dividing the change in $\triangle\left[\mathrm{HbO}_{2}\right](b)$ by area (a). (Reproduced with permission from Edwards et al, Lancet 1988; ii: $770-1$.)

\section{MAGNETIC RESONANCE IMAGING}

Several methods have been devised for the manipulation of magnetic resonance imaging data to provide information on cerebral perfusion, although this field is still at an early stage of development. ${ }^{8-10}$ Motion sensitising attenuation and/or detectable phase shifts in the signals from moving material dependent on the characteristics of the motion concerned. Secondly, 'time of flight effects' which utilise the paradoxical enhancement or attenuation of an image caused by flow during an imaging sequence are used. Thirdly, a paramagnetic contrast agent such as gadolinium-DTPA is used as a tracer for measurements using the Fick principle. This technique is very promising, both because it offers measurement of regional blood flow, and because, like NIRS, it can provide a wide array of additional data. Unfortunately it requires the infant to be transported to an MRI scanner and few data have yet been reported.

\section{NITROUS OXIDE TECHNIOUE}

The first quantitative measurement of CBF in humans was performed by Kety and Schmidt using $\mathrm{NO}_{2}$ as a tracer. When $\mathrm{NO}_{2}$ is inhaled, and $\mathrm{C}_{\mathrm{a}}$ and $\mathrm{C}_{\mathrm{v}}$ are monitored by repetitive gradient pulses can be used. These cause 
Figure 3 Distribution map of relative regional cerebral blood flow in a preterm infant, measured by ${ }^{99 \mathrm{~m}}$ TcHMPAO single photon emission tomography.

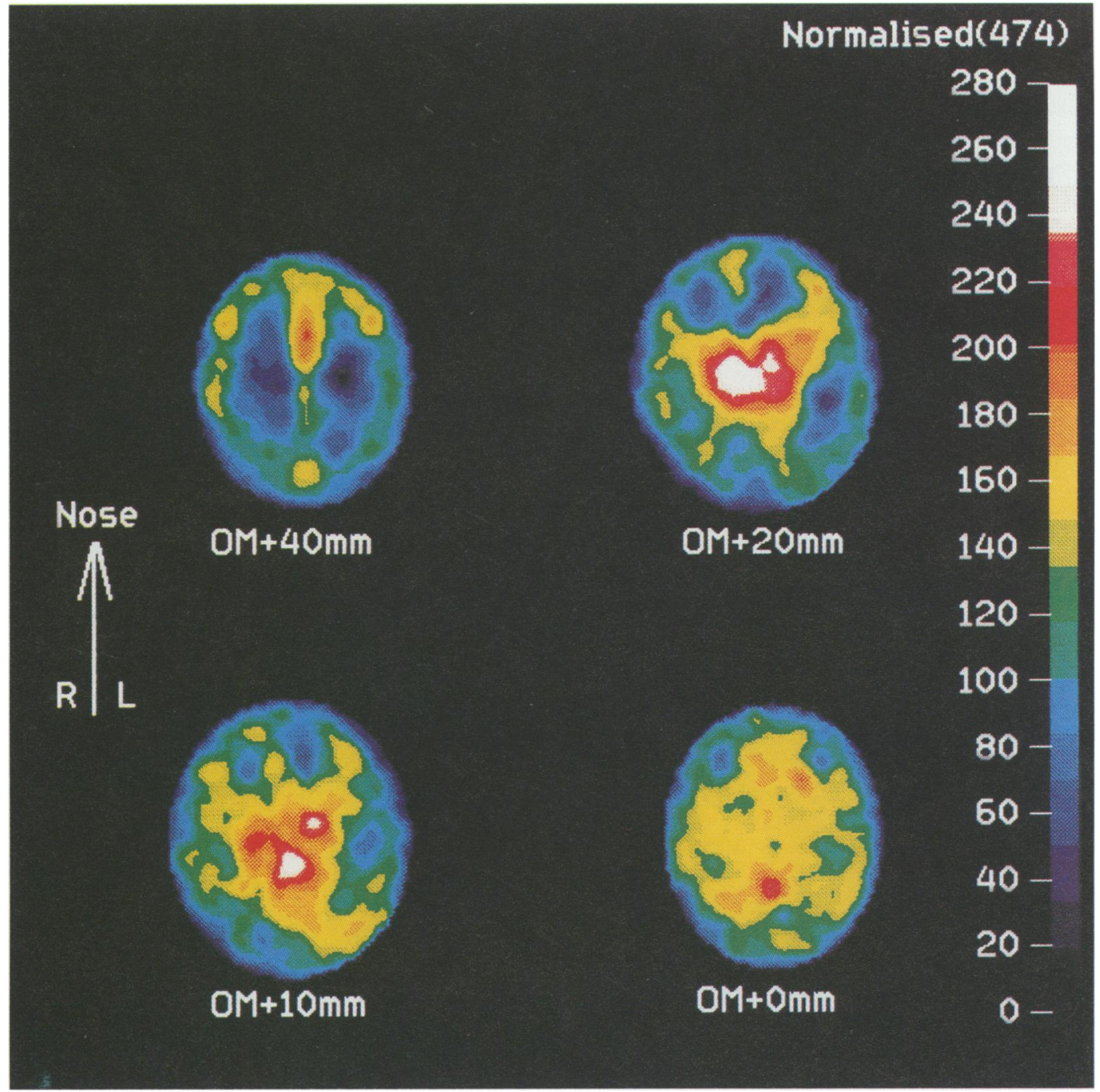

blood samplings, CBF can be derived by substituting $d Q$ with $d\left(C_{v}\right) \cdot \lambda$. Because arterial and cerebral venous catheterisation are required, only a few studies have been performed in neonates. ${ }^{11} 12$

\section{VENOUS OCCLUSION PLETHYSMOGRAPHY}

The skull of the newborn infant is relatively compliant, and will change in size with alterations of cerebral blood volume. The changes in cerebral circumference can be measured by impedance strain gauges and the change in cerebral volume inferred. Gentle occlusion of the jugular veins causes a small increase in cerebral blood volume and $\mathrm{CBF}$ can be estimated from the relation of changes in cerebral circumference and time. ${ }^{13}$ Problems in interpretation arise with the calculation of brain volume and with variations in skull compliance between infants, and the method has fallen from favour. However, the technique is remarkably simple and many warrant reassessment now that NIRS can be used to measure changes in cerebral blood volume more accurately.

\section{Non-quantitative observation of cerebral haemodynamics}

SINGLE PHOTON COMPUTED TOMOGRAPHY

Relative regional CBF has been observed in newborn infants using single photon tomography (SPECT) (Greisen et al, personal communication). This method requires injection of ${ }^{99} \mathrm{~m}$ TcHMPAO, which acts as a chemical microsphere: the radioactive ligand becomes trapped in the brain and can be imaged at some later time during its decay. The technique offers the potential for observing CBF during clinical events that would otherwise preclude research activities, such as pneumothorax or severe hypotension. The radioactivity image provides a distribution map of blood flow within the brain at the time of injection, although with less accuracy than PET. Relative regional CBF can be calculated, but unfortunately the values are only relative to each other, and absolute data cannot be obtained. Thus the distribution, but not the quantity of CBF, can be measured. This limits the comparison of data between infants, but it is hoped that the technique may aid understanding of the pathophysiology of periventricular leukomalacia and cerebral infarction. An example of SPECT data is given in fig 3. It shows a centripetal distribution of CBF at 26 weeks of postconceptional age.

DOPPLER ULTRASONOGRAPHY

A shift in frequency occurs when ultrasound is reflected from moving blood cells, and the shift 


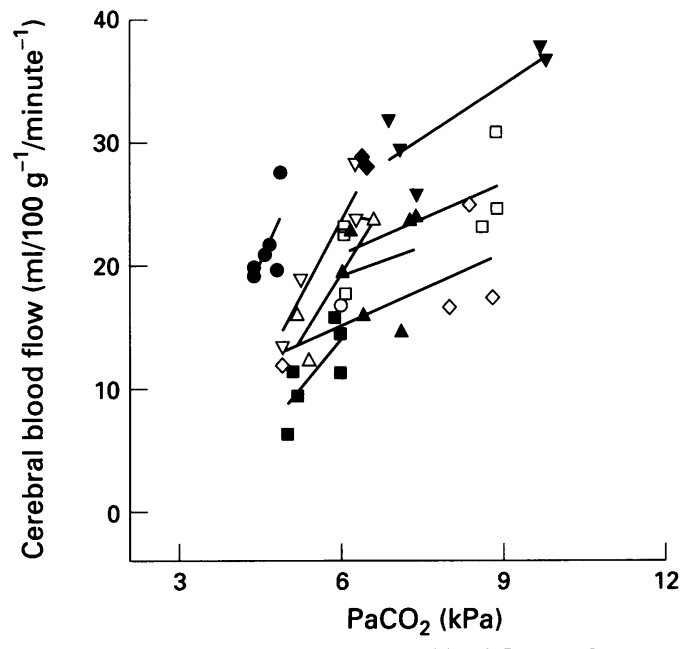

Figure 4 Relation between cerebral blood flow and arterial carbon dioxide tension in eight preterm infants, measured by near infrared spectroscopy. Each infant is denoted by a separate symbol and an individual regression line. (Reproduced with permission from Edwards et al, Ped Res 1992; 32: 532-6).

is proportional to the blood cell velocity. It is not possible to derive quantitative data on CBF from velocity as only one artery is insonated and its diameter remains unknown, but in certain circumstances Doppler ultrasonography may indicate trends in CBF. ${ }^{14}$

\section{The physiology of cerebral blood flow control}

CBF is determined by two factors: the resistance to blood flow in cerebral vascular channels, the cerebrovascular resistance (CVR); and the net pressure gradient across the cerebral vascular bed, the cerebral perfusion pressure (CPP). These are related such that:

$$
C B F=\frac{C P P}{C V R}
$$

\section{CEREBROVASCULAR RESISTANCE}

CVR is mainly determined by arteriolar tone, which is controlled by neuroeffector nerves, paracrine secretion from endothelial cells, circulating hormones and local humoral action. Data on the control of vascular tone in the brain of newborn infants are sparse, and most information has been provided from studies of animals.

Vascular tone is influenced by the balance of the different chemical signals, and a particular stimulus may elicit both vasoconstrictor and vasodilatory effects of great complexity. Important mediators include:

Prostanoids: Intracarotid injection of prostanoids (PGE1, PGE2, PGF2, PGI2) induces cerebral vasodilation in experimental animals, but the physiological roles in the regulation of CBF remains to be defined. ${ }^{15-17}$

Angiotensin: Cerebrovascular tone is partially maintained by angiotensin II produced locally in greater cerebral arteries, and in animals higher angiotensin concentrations widen the autoregulatory plateau (see below). ${ }^{18}$
Nitric oxide: Endothelial cells respond to physical and chemical stimuli by secreting a series of factors which cause constriction (such as endothelin) or dilation. Nitric oxide (NO) is a vasodilator which is also released from perivascular nerves and neural cells. NO is released constitutively to mediate a constant vasodilator tone, and also in response to stimuli including increased shear stress. Inhibition of endogenous NO synthesis leads to a moderate decline in cerebral blood flow and volume in newborn piglets but the effect seems to be less than that of indomethacin. ${ }^{19} 20$ $\mathrm{NO}$ is produced by inflammatory cells and may have a role in the vasodilation caused by sepsis.

Perivascular nerves: Cerebral arteries and arterioles are supplied by sympathetic, cholinergic, and peptidergic nerves. In addition to classic neurotransmitters such as noradrenaline and acetylcholine, many other transmitters have been identified. Nerves usually release two substances together as co-transmitters: ATP and noradrenaline are released together from some sympathetic nerves, where ATP seems to elicit a rapid, shortlived response while noradrenaline has a slower and longer action. The parasympathetic neurons also demonstrate co-transmission in that acetylcholine and vasoactive intestinal peptide are released together and cause vasodilation. ${ }^{21}$

Catecholamines: Infusion of noradrenaline or adrenaline causes noticeable cerebral vasoconstriction in newborn infants, although this effect can be rapidly attenuated (Edwards $e t a l$, unpublished data). Systemic catecholamines have many actions, including profound effects on cardiac output and systemic blood pressure, and an increase in cerebrovascular tone may protect cerebral capillaries from sudden surges in arterial blood pressure. ${ }^{22}$

CEREBRAL PERFUSION PRESSURE

CPP is determined by the difference between arterial pressure and the cerebral venous pressure. In normal circumstances venous pressure is very much lower than arteriolar pressure and contributes little to CVR. However, it has been suggested that pathological situations such as tension pneumothorax, which lead to very high venous pressures, can disrupt CBF sufficiently to cause cerebral infarction in the preterm infant. Raised intracranial pressure may also cause cerebral venous pressure to the point where it contributes significantly to CVR with risk of cerebral hypoperfusion. ${ }^{23}$ Unfortunately direct evidence to substantiate these hypotheses is difficult to obtain.

\section{Cerebral blood flow and metabolism}

Absolute values of global CBF can be misleading as there is rapid and constant readjustment of regional blood flow to satisfy local metabolic requirements. Relatively low neuronal activity in the newborn brain means that metabolism can be maintained by a global CBF of 10 to 20 $\mathrm{ml} / 100 \mathrm{~g} / \mathrm{minute}$, about one third of the value 
for the healthy adult brain. CBF is tightly coupled to metabolic demands for oxygen and glucose and is strongly affected by the byproducts of metabolism.

CBF is inversely related to the arterial oxygen content $\left(\mathrm{C}_{\mathrm{a}} \mathrm{O}_{2}\right)$ which is determined by the haemoglobin concentrations, the oxygen affinity of haemoglobin, and $\mathrm{P}_{\mathrm{a}} \mathrm{O}_{2} \cdot{ }^{24-26}$ The dissociation characteristics of oxygenated haemoglobin mean that changes in $\mathrm{C}_{\mathrm{a}} \mathrm{O}_{2}$ have little effect on CBF until $\mathrm{P}_{\mathrm{a}} \mathrm{O}_{2}$ falls below 5-6 $\mathrm{kPa}$, but further falls occasion significant increases in CBF. One study also suggested that hyperoxia immediately after birth can lead to a prolonged reduction in $\mathrm{CBF}^{27}$

Hypoglycaemia is accompanied by a two- to threefold increase in CBF. ${ }^{28-30}$ In case of the prolonged glucose restriction associated with placental dysfunction, cerebral hyperperfusion may persist for days after normoglycaemia has been established. ${ }^{31}$

The cerebral vessels are very sensitive to changes in $\mathrm{P}_{\mathrm{a}} \mathrm{CO}_{2}$ as carbon dioxide readily passes the blood-brain barrier and alters the perivascular $\mathrm{pH}^{32}$ Hypercapnia induces cerebral vasodilatation and a rise in $\mathrm{CBF}$ of about $30 \%$ per $\mathrm{kPa}^{33}$ The response is probably mediated by perivascular bicarbonate concentration, ${ }^{34}$ and so the $\mathrm{CBF}-\mathrm{CO}_{2}$ reactivity is attenuated during chronic hypercapnia and enhanced during chronic hypocapnia. 3536 Studies in adults and animals have suggested that $\mathrm{NO}$ mediates $\mathrm{CBF}-\mathrm{CO}_{2}$ reactivity, ${ }^{37}$ but this does not seem to be the case in the newborn. ${ }^{19}$ Reduced responsiveness to $\mathrm{CO}_{2}$ is also observed after indomethacin, ${ }^{38}$ when the vessels are maximally dilated because of concomitant hypotension, hypoxia, or hypoglycaemia, ${ }^{3940}$ or following asphyxia. The relation of $\mathrm{CBF}$ to $\mathrm{P}_{\mathrm{a}} \mathrm{CO}_{2}$ in eight newborn infants is shown in fig 4 .

Some byproducts of energy metabolism may effect the coupling between metabolic requirements and CBF. Adenosine has a strong vasodilator effect, and adenosine concentration in the brain increases during electrical stimulation or seizure activity. In the immediate vicinity of pial arterioles the potassium ion produces dose-related vasodilatation whereas local application of calcium causes vasoconstriction. ${ }^{41}$

\section{Cerebral blood flow and arterial blood pressure}

Pressure autoregulation, defined as a constant CBF within a wide range of arterial blood pressures (the 'autoregulatory plateau'), is fully developed in fetal and neonatal animals. ${ }^{424}$ Methodological and ethical constraints have prevented it from being appropriately investigated in newborn infants but preliminary results show that $\mathrm{CBF}$ remains constant during small and spontaneous changes in blood pressure. ${ }^{34}$

In animals the autoregulatory plateau is not fixed but depends on the actual diameter of the vessels determined by other factors such as $\mathrm{P}_{2} \mathrm{CO}_{2}$ and $\mathrm{C}_{2} \mathrm{O}_{2}$. Pressure autoregulation becomes impaired when vasodilatation occurs during hypercapnia, hypoxia, hypoglycaemia or seizures, whereas vasoconstriction widens the autoregulatory plateau. ${ }^{44}$

\section{The effect of blood viscosity on cerebral blood flow}

The resistance to blood flow increases with higher haematocrit, and hence CBF tends to decrease. This fall, however, is partially caused by the concomitant rise in oxygen carrying capacity which is highly related to the haematocrit. ${ }^{45}$

This association between increased haematocrit and lower CBF has been well established in adults, and haematocrits greater than 0.7 lead to a significant risk of cerebral ischaemia. In the newborn infant blood viscosity is lower for a given haematocrit than in the adult, due to differences in both plasma components and red cell deformability. Data are not available to decide clearly on the upper limit for a safe haematocrit in the newborn infant, although many clinicians extrapolate from studies in adults for their everyday practice.

\section{Pharmacological agents and cerebral \\ blood flow}

Direct measurements of the effects of only a few pharmacological substances have been made in newborn infants:

Indomethacin reduced $\mathrm{CBF}$ in newborn infants by 20 to $40 \%$ when given intravenously at therapeutic doses of 0.10 or $0.20 \mathrm{mg} / \mathrm{kg}$. ${ }^{38} 46$ In newborn piglets this effect is not observed after administration of Ibuprofen, ${ }^{47}$ and preliminary data suggest that this is also true in newborn infants. ${ }^{48}$

Dopamine administered to treat hypotension leads to a simultaneous increase in arterial blood pressure and cerebral blood flow (Pryds, et al, unpublished data).

A small reduction in CBF (10-15\%) was shown after intravenous administration of Aminophylline, which is an antagonist of adenosine. ${ }^{49}$

When the metabolic rate is reduced by sedatives or hypothermia, CBF decreases in association with the reduced metabolic demand. 5051

\section{Cerebral blood flow and cerebral injury LOW CEREBRAL BLOOD FLOW}

The lower threshold of $\mathrm{CBF}$ to sustain neuronal integrity is unknown in newborn infants as a normal neurological outcome is still possible with $\mathrm{CBF}$ as low as $5 \mathrm{ml} / 100$ g/minute. ${ }^{35253}$ Indeed, CBF cannot be used alone as an indicator of the brain's condition as a low flow state may either be normal or pathological. In order to distinguish between normal and abnormal, values for CBF have to be related to oxygen consumption $\left(\mathrm{CMRO}_{2}\right)$ and oxygen extraction (OER).

When low CBF is coupled to a depressed cerebral function induced, for example, by sedatives or hypothermia, OER may remain normal, implying that $\mathrm{CBF}$ and $\mathrm{CMRO}_{2}$ are 
properly matched. However, OER will increase when CBF drops without a concomitant change in $\mathrm{CMRO}_{2}$, and this can be most easily observed as increasing desaturation in cerebral venous blood. In newborn dogs maximal OER occurs when the oxygen saturation of cerebral venous blood is about 0.4 , and any further decline in oxygen delivery will lead to ischaemia. ${ }^{54}$

\section{HIGH CEREBRAL BLOOD FLOW}

Hypoxia, hypercapnia, hypoglycaemia, and anaemia are associated with a rise in CBF which maintains normal $\mathrm{CMRO}_{2}$. However, in the hours following severe perinatal hypoxic-ischaemic injury a significant cerebral hyperperfusion has been observed which seems to be associated with reduced rather than increased $\mathrm{CMRO}_{2}{ }^{125556}$ The mechanism of this 'luxury perfusion' is unclear, although in fetal sheep it is mediated in part by NO production. ${ }^{57}$ The precise relation between delayed hyperperfusion following hypoxia-ischaemia and delayed impairments in cerebral energy metabolism is still unresolved, but in infants with birth asphyxia hyperperfusion is a sign of poor neurodevelopmental prognosis, particularly when accompanied by loss of pressure autoregulation and $\mathrm{CO}_{2}$ reactivity. ${ }^{55}$

\section{Conclusion}

Studies of CBF have provided some insight into cerebrovascular physiology and pharmacology. However, the precise relation between $\mathrm{CBF}$ and cerebral damage remains elusive, and there is no definition of a threshold CBF below which ischaemic brain damage always occurs. Measurement of CBF thus does not currently provide a secure guide in the clinical management of sick infants. Further work, particularly using techniques like magnetic resonance imaging and NIRS, which provide data in addition to CBF measurements, may yet disclose strategies which manipulate CBF to reduce cerebral ischaemia. While cerebral injury remains a substantial problem in neonatal intensive care, such research is urgently needed.

We are grateful for the financial support of the Vilie Heise Foundation, the Dagmar Marshall Foundation, Beckett's Foundation, and the Torben Iversens Foundation.

1 Pape KE, Wigglesworth JS. Haemorrhage, ischaemia and the perinatal brain. Clinics in developmental medicine 69/70. London: Spastics International Medical Publications, 979: 1-196

2 Greisen G, Pryds O. Intravenous ${ }^{133} \mathrm{Xe}$ clearance in preterm neonates with respiratory distress. Internal validation of CBF0 as a measure of global cerebral blood flow. Scand f Clin Lab Invest 1988; 48: 673-8.

3 Altman DI, Perlman JM, Volpe JJ, Powers WJ. Cerebral oxygen metabolism in newborns. Pediatrics 1993; 92: 99-104.

4 Ashwal S, Schneider S, Thompson J. Xenon computed tomography measuring cerebral blood flow in the determination of brain death in children. Ann Neurol 1989; 25: 539-46.

5 Jobsis FF. Noninvasive infrared monitoring of cerebral and myocardial oxygen sufficiency and circulatory parameters. Science 1977; 198: 1264-7.

6 Skov LL, Pryds O, Greisen G. Estimating cerebral blood flow in newborn infants: Comparison of near infrared spectroscopy and ${ }^{133}$ Xe-clearance. Ped Res 1991; 30: 570-3.

7 Edwards AD, Wyatt JS, Richardson C, Delpy DT, Cope M,
Reynolds EOR. Cotside measurement of cerebral blood flow in ill newborn infants by near infrared spectroscopy. Lancet 1988; ii: 707-11.

8 Smith MA. The measurement and visualisation of vessel blood flow by magnetic resonance imaging. Clin Phys Physiol Meas 1990; 11: 101-23.

9 Ogawa S, Lee-T-M, Nayak AS, Glynn P. Oxygenationsensitive contrast in magnetic resonance image of rodent brain at high magnetic fields. Magnet Reson Med 1990; 14: 68-78.

10 Belliveau JW, Kennedy DN, McKinstry RC, Buchbinder BR, Weiskoff RM, Cohen MS, et al. Functional mapping of the human visual cortex by magnetic resonance imagof the human visual cortex by
ing. Science 1991; 254: 716-9.

11 Settergren G, Lindblad BS, Persson B. Cerebral blood flow and exchange of oxygen, glucose, ketone bodies, lactate, pyruvate and amino acids in infants. Acta Paediatr Scand 1976; 65: 343-53.

12 Frewen TC, Kissoon N, Kronick J, Fox M, Lee R, Bradwin $\mathrm{N}$, et al. Cerebral blood flow, cross-brain oxygen extraction, and fontanelle pressure after hypoxic-ischemic injury in newborn infants. $\mathcal{F}$ Pediatr 1991; 118: 265-71.

13 Cooke RWI, Rolfe P, Howat P. Apparent cerebral blood flow in newborns with respiratory disease. Dev Med Child Neurol 1979; 21: 154-60.

14 Thoresen M, Haaland K, Steen PA. Cerebral Doppler and misinterpretation of flow changes. Arch Dis Child 1994; 71: $103-6$.

15 Leffler CW, Busija DW. Arachidonic acid metabolites and perinatal cerebral hemodynamics. Semin Perinatol 1987; 11: $31-42$.

16 Rennie JM, Doyle J, Cooke RWI. Elevated levels of immunoreactive prostacyclin metabolite in babies who develop intraventricular haemorrhage. Acta Paediatr Scand 1987; 76: 19-23.

17 Aranda JV, Beharry K, Sasyniuk B, Chemtob S. The role of prostanoids in neonatal cerebral blood flow autoregulation. $千$ Lipid Mediat 1993; 6: 493-501.

18 Paulson OB, Waldemar G, Andersen AR, Barry DI, Pedersen EV, Schmidt JF, et al. Role of angiotensin in autoregulation of cerebral blood flow. Circulation 1988; 77: 55-8.

19 Patel J, Pryds O, Roberts I, Harris D, Edwards AD. Effect of L-nitro-arginine methyl ester (L-NAME) on cerebra blood flow in newborn piglets. Early Hum Dev (in press).

20 Takei Y, Edwards AD, Lorek A, Peebles DM, Belai A Cope M, et al. Effects of N-omega-nitro-L-arginine methyl ester on the cerebral circulation of newborn piglets quantified in vivo by near-infrared spectroscopy. Ped Res 1993; 34: 354-9.

21 Burnstock G. Local mechanisms of blood pressure control. f Hypertension 1990; 8: S95-106.

22 Wagerle LC, Kurth CD, Roth RA. Sympathetic reactivity of cerebral arteries in developing fetal lamb and adult sheep. Am f Physiol 1990; 258: H1432-8.

23 Langfitt TW, Weinstein JD, Kassel NF. Cerebral vasomotor paralysis produced by intracranial hypertension. Neurology 1965; 15: 622-41.

24 Jones MD, Traystman RJ, Simmons MA, Molteni RA Effects of changes in arterial $\mathrm{O}_{2}$ content on cerebral blood flow in the lamb. Am $\mathcal{F}$ Physiol 1981; 240: H209-15.

25 Pryds $\mathrm{O}$, Greisen $\mathrm{G}$. The effect of $\mathrm{PaCO}_{2}$ and haemoglobin concentration on the day to day variation of $\mathrm{CBF}$ in preterm neonates. Acta Paediatr Scand 1989; Suppl 360 334.

26 Lipp-Zwahlen AE, Muller A, Tuchschmid P, Duc G. Oxygen affinity of haemoglobin modulates cerebral blood flow in premature infants: A study with the non-invasive Xenon-133 method. Acta Paediatr Scand 1989; Suppl 360: 26-32.

27 Nijima S, Shortland DB, Levene MI, Evans DH. Transient hyperoxia and cerebral blood flow velocity in infants born prematurely and at full term. Arch Dis Child 1988; 63 1126-30.

28 Mujsce DJ, Christensen MA, Vannucci RC. Regional cerebral blood flow and glucose utilization during hypoglycemia in newborn dogs. Am $\mathcal{f}$ Physiol 1989; 256: H1659-66.

29 Pryds O, Greisen G, Friis-Hansen B. Compensatory increase of CBF supports the cerebral metabolism in preterm infants during hypoglycaemia. Acta Paediatr Scand 1988; 77: 632-7.

30 Pryds O, Christensen NJ, Friis-Hansen B. Increased CBF and plasma epinephrine in hypoglycemic, preterm infants. Pediatrics 1990; 85: 172-6.

31 Bryan RM, Pelligrino DA. Cerebral blood flow during chronic hypoglycemia in the rat. Brain Res 1988; 475: $397-400$.

32 Skinhoj E, Paulson O. The local site of action of $\mathrm{CO}_{2}$ on cerebral circulation evidenced by changing the internal carotid artery $\mathrm{PCO}_{2}$ in awake human subjects. Scand $\mathcal{F}$ Lab Clin Invest 1968; Suppl 102: VII:F.

33 Pryds O, Andersen GE, Friis-Hansen B. Cerebral blood flow reactivity in spontaneously breathing, preterm infants shortly after birth. Acta Paediatr Scand 1990; 79: 391-6.

34 Levasseur JE, Wei EP, Kontos HA, Patterson JL. Responses of pial arterioles after prolonged hypercapnia and hypoxia in the awake rabbit. $f$ Appl Physiol 1979; 46: 89-95.

35 Pryds O, Greisen G, Lou H, Friis-Hansen B. Heterogeneity of cerebral vasoreactivity in preterm infants supported by mechanical ventilation. $\mathcal{F}$ Pediatr 1989; 115: 638-45.

36 Greisen G, Trojaborg W. Cerebral blood flow, $\mathrm{P}_{\mathrm{CO}}$ changes, and visual evoked potentials in mechanically ventilated, preterm infants. Acta Paediatr Scand 1987; 76: $394-400$. 
37 Wang $Q$, Pelligrino DA, Paulson OB, Lassen NA Comparison of the effects of $\mathrm{N}^{\mathrm{G}}$-nitro-L-arginine and indomethacin on the hypercapnic cerebral blood flow increase in rats. Brain Res 1994; 641: 257-64.

38 Edwards AD, Wyatt JS, Richardson C, Potter A, Cope $M$ Delpy DT, Reynolds EOR. Effects of indomethacin on cerebral haemodynamics in very preterm infants. Lance 1990; 335: 1491-5.

39 Haggendal E, Winso I. The influence of arterial carbon dioxide tension on the cerebrovascular response to arterial hypoxia and to haemodilution. Acta Anaesth Scand 1975; 19: $134-45$.

40 Nilsson $B$, Agardh CD, Ingvar M, Siesjo BK Cerebrovascular response during and following severe insulin-induced hypoglycemia: $\mathrm{CO}_{2}$-sensitivity, autoregulation, and influence of prostaglandin synthesis inhibition. Acta Physiol Scand 1981; 111: 455-63.

41 Betz E, Csornal $M$. Action and interaction of perivascula $\mathrm{H}^{+}, \mathrm{K}^{+}$and $\mathrm{Ca}^{++}$on pial arteries. Pfluegers Arch 1978 374: 79-88.

42 Hernandez MJ, Brennan RW, Bowman GS. Autoregulation of cerebral blood flow in the newborn dog. Brain Res 1980; 184: 199-202.

43 Pasternak JF, Groothuis DR. Autoregulation of cerebral blood flow in the newborn beagle puppy. Biol Neonate 1985; 48: 100-9.

44 Van-Bel F, Klautz RJ, Steendijk P, Schipper IB, Teitel DF Baan J. The influence of indomethacin on the autoregulaBaan J. The influence of indomethacin on the autoregulatory ability of the cerebral vascular

45 Hudak ML, Tang Y, Massik J, Koehler RC, Traystman RJ, Jones $M D$. Base line $\mathrm{O}_{2}$ extraction influences cerebra blood flow response to hematocrit. Am $\mathcal{f}$ Physiol 1988 254: H156-62.

46 Pryds O, Greisen G, Johansen KJ. Indomethacin and cerebral blood flow in premature infants treated fo patent ductus arteriosus. Eur $\mathcal{f}$ Pediatr 1988; 147: $315-6$.

47 Chemtob S, Beharry K, Bama T, Varma DR, Aranda JV.
Differences in the effects in the newborn piglet of various nonsteroidal antiinflammatory drugs on cerebral blood flow but not on cerebrovascular prostaglandins. Ped Res 1991; 30: 106-11.

48 Patel J, Marks K, Roberts I, Azzopardi D, Edwards AD. lbuprofen treatment of patent ductus arteriosus. Lancet 1995; 346: 255 .

49 Pryds O, Schneider S. Aminophylline induces cerebral vasoconstriction in stable, preterm infants without affecting the visual evoked potential. Eur $\mathcal{F}$ Pediatr 1991; 150: 366-9.

50 Baughman VL, Hoffman WE, Miletich DJ, Albrecht RF. Effects of pheno barbital on cerebral blood flow and metabolism in young and aged rats. Anaesthesiology 1986; metabolism $500-5$.

51 Busija DW, Leffler CW. Hypothermia reduces cerebral metabolic rate and cerebral blood flow in newborn pigs. Am ₹ Physiol 1987; 253: H869-73.

52 Pryds O, Greisen G. Preservation of single flash visual evoked potentials at very low cerebral oxygen delivery in sick newborn, preterm infants. Pediatr Neurol 1990; 6: 151-8.

53 Pryds $\mathrm{O}$. Low neonatal cerebral oxygen delivery is associated with brain injury in preterm infants. Acta Paediatr 1994; 83: 1233-6.

54 Reuter JH, Disney TA. Regional cerebral blood flow and cerebral metabolic rate of oxygen during hyperventilation in the newborn dog. Ped Res 1986; 20: 1102-6.

55 Pryds O, Greisen G, Lou H, Friis-Hansen B. Vasoparalysis is associated with brain damage in asphyxiated term infants. F Pediatr 1990; 117: 119-25.

56 Skov L, Pryds O, Greisen G, Lou H. Estimation of cerebral venous saturation in newborn infants by near infrared spectroscopy. Ped Res 1993; 33: 52-5.

57 Marks KA, Mallard EC, Roberts I, Williams CE, Gluckman PD, Edwards AD. N8-Nitro-L-arginine, anitric oxide synthesis inhibitor, alters the delayed changes in cerebral haemodynamics that follow transient cerebral ischaemia in fetal sheep. Early Hum Dev (in press). 